\title{
In Situ Biodiesel Production from Residual Oil Recovered from Spent Bleaching Earth
}

\author{
Ramli Mat *, Ow Shin Ling, Anwar Johari, Mahadhir Mohamed \\ Department of Chemical Engineering, Faculty of Chemical Engineering, Universiti Teknologi \\ Malaysia, 81310 UTM Skudai, Johor, MALAYSIA
}

Received: 19th December 2010; Revised: 10th May 2011; Accepted: 18th May 2011

\begin{abstract}
Currently, semi-refined and refined vegetable oils are used as a feedstock in biodiesel production. However, due to competition with conventional fossil fuel, economic reasons, shortage supply of food and its social impact on the global scale has somewhat slowed the development of biodiesel industry. Studies have been conducted to recover oil from mill palm oil operation especially from the spent bleaching earth. Hence, the study was to investigate the potential recovery of oil from spent bleaching earth to be used as a feedstock for biodiesel production. The effect of different types of catalysts (sodium hydroxide alkali and sulfuric acid catalysts) on biodiesel yield was studied. In addition, the effect of volume addition of methanol to the weight of spent bleaching earth on the product yield was also studied. Furthermore, the effect of ratio of hexane to methanol was also carried out to determine its product yield. The studies were carried out in an in-situ biodiesel reactor system and the biodiesel product was analyzed using gas chromatography mass spectrometry. Result shows that the use of alkali catalyst produced the highest yield of biodiesel and the most optimum biodiesel yield was obtained when the methanol to spent bleaching earth ratio was 3.2:1 (gram of methanol: gram of SBE) and hexane to methanol ratio of 0.6:1 (volume of hexane: volume of methanol). (C) 2011 BCREC UNDIP. All rights reserved
\end{abstract}

Keywords: Spent bleaching earth, in situ trans-esterification, biodiesel, residual oil

\section{Introduction}

Palm oil industry has emerged since early 20th century and it is widely used in food and cosmetic sectors. Bleaching earth is used to produce better quality of oil by removing colouring substances and trace elements in crude palm oil. Rapid increase in global population has causes an increase in palm oil production; hence, spent bleaching earth (SBE) disposal problems constitute a significant economic waste and an environmental burden. About 1.5-2.0 million tons of SBE are produced worldwide annually, and it is estimated that $30 \%$ of oil in the SBE could be recovered [1].

* Corresponding Author.

E-mail address: ramli@cheme.utm.my (Ramli Mat), Tel: +06-07-5535507, Fax: +06-07-5536165
Past practice shows that the spent bleaching earth is normally land filled. However, strong resistance from environmentalists and potential economics returns from recycling of this material has generated substantial interest towards the recovery of oil from SBE [2]. The recovered oil is later subjected to further processing for value added product such as biodiesel via transesterification process.

Generally, alkaline catalyst is used in transesterification of biodiesel for its fast performance. However, alkaline catalyst is sensitive towards water and the SBE is normally heated to $100^{\circ} \mathrm{C}$ for the removal of moisture content before the reaction commences. If the moisture and excessive free fatty acid content are more than $0.5 \%$ in SBE, the formation of unwanted soap would occur and result 
in the deactivation of catalyst [3]. In industry processes, esterification was first carried out to recover oil for the reduction of free fatty acid content prior to trans-esterification process. However, it would be costly and time consuming if the esterification could not reduce the free fatty acid content to desired percentage, which is below $2 \%$. On the other hand, acidic catalyst which is less sensitive to free fatty acid can prevent the formation of soap but needs longer reaction time.

Most commercial biodiesels are produced from edible vegetable oils which are expensive. One way of reducing biodiesel production costs is to use low cost raw material such as oil recovered oil from the SBE which contain about $30 \%$ oil. A two-step catalyzed chemical reaction has been developed to recover oil from the SBE [1]. The economic competitiveness of biodiesel can be significantly improved by applying an "in-situ process". It is estimated that about 600,000 metric tons or more of bleaching earth are utilized worldwide in the refining process based on the worldwide production of more than 60 million tons of oils. The SBE serves as by-product, which contains high percentage of oil.

The SBE generated annually by Malaysian palm oil refineries is estimated to be approximately 120000 tons. The potential oil that can be recovered is estimated to be approximately 36000 tons [4]. Thus it is highly potential to recover the oil by using in situ method for biodiesel production. The research is intended to recover the oil from the SBE for the production of biodiesel using in situ process. In addition, the effects of acid and alkaline catalysts on the yield of biodiesel, mass ratio of methanol to $\mathrm{SBE}$ and the ratio of hexane to methanol on in situ process are also highlighted

\section{Materials and Method}

\subsection{Determination of Oil Content}

10 gram of SBE was weighed and put in a furnace at $100^{\circ} \mathrm{C}$ for 24 hours. It was later removed and reweighted which signifies the removal of moisture content from the sample. The moisture free sample was then heated to $400^{\circ} \mathrm{C}$ in the furnace for 24 hours for the oil removal process since the boiling point for oil is estimated at $300^{\circ} \mathrm{C}$ [5]. The weight difference of SBE at $100^{\circ} \mathrm{C}$ and $400^{\circ} \mathrm{C}$ indicates the weight of oil in SBE. The process is repeated three times for accurate results.

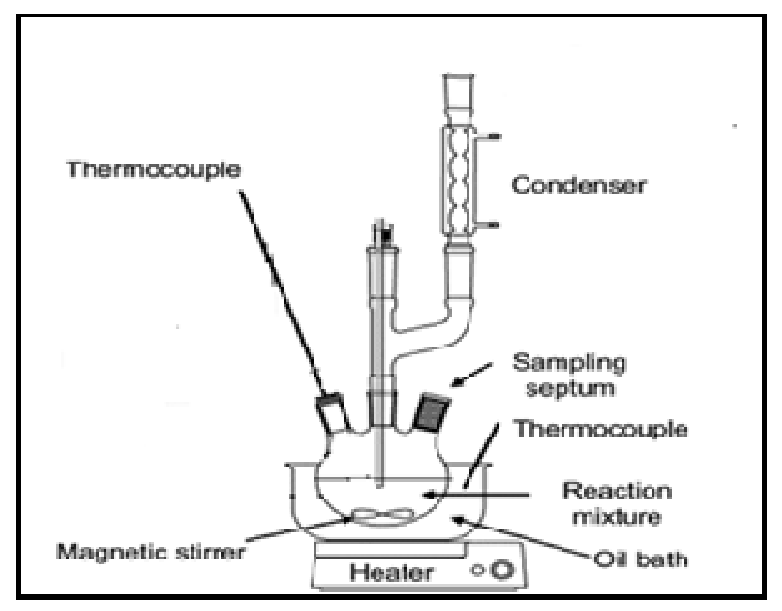

Figure 1. Reactor System for 'in-situ' Biodiesel Production

\subsection{In Situ Biodiesel Production from Oil Recovered from SBE}

The experiments were carried out into two stages. The first step was to study the effect of types of catalyst on the yield of biodiesel. In this case, sodium hydroxide alkali and sulfuric acid catalysts were used. Hence, at this stage, the volume of methanol and hexane was fixed at 100 $\mathrm{ml}$ for both chemicals throughout the study. The second stage of the study dealt with the effect of ratio between methanol to SBE on the selected catalyst chosen from the first stage. It was continued with the study of the effect of ratio between hexane to methanol for the maximum performance of biodiesel production. The reactor system used in the experiment is shown in Figure 1.

\subsubsection{Study on the Effect of Catalyst Types on the Performance of Biodiesel Production}

50 gram of moisture free SBE was weighed while catalyst (sodium hydroxide alkali), methanol $(100 \mathrm{ml})$ and hexane $(100 \mathrm{ml})$ were stirred together in the beaker to generate homogeneous mixture. SBE, hexane and mixture of methanol and catalyst were then poured into round bottom flask and heated using oil bath which was preheated at $65^{\circ} \mathrm{C}$ for 24 hours with stirring speed of $600 \mathrm{rpm}$. The setup was refluxed with condenser to prevent evaporation of methanol and hexane since boiling point of methanol and hexane is $64.7^{\circ} \mathrm{C}$ and $68.74^{\circ}$ $\mathrm{C}$ respectively. Hexane was used in the study to extract the oil from SBE.

The round bottom flask was later removed from oil bath. The product was filtered by using vacuum 
filter. Then, the filtered product was allowed to be separated in separating funnel for overnight. The upper layer of product was collected and washed using distilled water and shaken appropriately to remove the residual methanol. The product was then allowed to be separated in separation funnel again for the removal of water and impurities and kept overnight. The upper layer of product was collected and heated to $80^{\circ} \mathrm{C}$ to remove residual solvents. The weight of final product was determined and analyzed using gas chromatography mass spectrometry. The process was repeated with sulfuric acid as the catalyst. The biodiesel yield was calculated using the following equation.

$\%$ yield of biodiesel $=\frac{\text { gram of biodiesel produced }}{\text { gram of } 38 E} \times 100 \%$

\subsubsection{Study on the Effect of Methanol to SBE Ratio}

Methanol plays a vital role in production of biodiesel. In trans-esterification, stoichiometric molar ratio of methanol and oil is $3: 1$, however, excess methanol is needed to increase the yields of the alkyl esters and to allow its phase separation from the glycerol formed [6]. Six experiments were conducted according to different methanol to SBE ratios at reaction temperature of $65^{\circ} \mathrm{C}, 5$ hours of reaction time and $2 \mathrm{wt} \%$ of the selected catalyst. The weight and volume of SBE and hexane were fixed at $50 \mathrm{~g}$ and $100 \mathrm{ml}$ respectively.

\subsubsection{Study on the Effect of Hexane to Methanol Ratio}

A non polar solvent hexane was used to extract residual oil form spent bleaching earth. Lee et al. [7] reported that extracted oil from polar solvent such as alcohol was much darker than those extracted using non polar solvent. Hexane was described as the best solvent that yielded lower percentage of free fatty acid presence in extracted oil [7]. The volume addition of hexane was varied to improve the extraction rate of oil from SBE. The process was conducted using $65^{\circ} \mathrm{C}$ reaction temperature, 5 hours reaction time and $2 \mathrm{wt} \%$ of the selected catalyst. The amount of SBE and methanol was fixed at $50 \mathrm{~g}$ and $200 \mathrm{ml}$ respectively.

\section{Results and Discussion}

\subsection{Determination of Oil Content}

SBE contains moisture, residual oils and impurities that arise during degumming, decolourization and deodorization processes. The average oil content in SBE was $38.13 \%$, which is in the range of $20 \%$ to $40 \%$ by weight as reported by Taylor et al. [8].

\subsection{Effect of Types of Catalyst on Biodiesel Production}

The effect of alkali and acid catalyst on the production of biodiesel was investigated. Comparisons were made based on its product yield, completed reaction time as well as its separation quality. Table 1 shows the outcome of the process using both catalysts.

The use of alkali catalyst resulted in the formation of two distinct layers in which biodiesel was visible at the upper layer and glycerol at the bottom. On the other hand, the use of acid catalyst has resulted in a single layer only with no visible separation of the products. Product analyses formed by GC-MS revealed that alkali catalyst produced higher purity of biodiesel than acid catalyst. Furthermore, alkali catalyst needed shorter reaction time than acid catalyst for complete trans-esterification reactions which is similar to report published by Schuchardt et al. [6].

Another drawback of acid catalyst usage is the need of larger methanol to oil ratio as described by Demirbas [9]. In addition, the equipment for the biodiesel production may corrode faster and thus increase the maintenance cost. In view of these results, the alkali catalyst was chosen for further studies involving the effect of methanol to SBE ratio and hexane to methanol ratio.

Table 1. Comparison Results of Usage of Acid and Alkali Catalysts

\begin{tabular}{lll}
\hline & $\begin{array}{c}\text { Sodium hy- } \\
\text { droxide } \\
\text { catalyst }\end{array}$ & \multicolumn{1}{c}{$\begin{array}{c}\text { Sulfuric acid } \\
\text { catalyst }\end{array}$} \\
\hline $\begin{array}{l}\text { After overnight } \\
\text { separation }\end{array}$ & Two layers & One layer \\
$\begin{array}{l}\text { Reaction time } \\
\text { for completion }\end{array}$ & $\begin{array}{l}\text { Shorter } \\
\text { reaction } \\
\text { time } \\
(1-5 \text { hours) }\end{array}$ & $\begin{array}{l}\text { Longer reaction } \\
\text { time (More } \\
\text { than 5 hours) }\end{array}$ \\
$\begin{array}{l}\text { Yield of bio- } \\
\text { diesel (wt\% bio- }\end{array}$ & $\begin{array}{l}\text { More than } \\
\text { diesel/SBE) }\end{array}$ & Less than 5\% \\
Corrosiveness & Less & More \\
\hline
\end{tabular}


Table 2. Biodiesel Yield Using Different Methanol to $50 \mathrm{~g}$ SBE Ratio with $100 \mathrm{ml}$ of Hexane

\begin{tabular}{llll}
\hline $\begin{array}{l}\text { Experi- } \\
\text { ment } \\
\text { No. }\end{array}$ & $\begin{array}{l}\text { Methanol } \\
\text { (ml) }\end{array}$ & $\begin{array}{l}\text { Bio- } \\
\text { diesel } \\
\text { Product } \\
\text { Weight } \\
\text { (gram) }\end{array}$ & $\begin{array}{l}\text { Yield } \\
\text { of Bio- } \\
\text { diesel } \\
\text { (\%) }\end{array}$ \\
\hline 1 & & 1.40 & 2.17 \\
2 & 75 & 3.10 & 5.55 \\
3 & 100 & 4.79 & 8.52 \\
4 & 125 & 6.03 & 11.56 \\
5 & 150 & 7.89 & 15.57 \\
6 & 175 & 8.09 & 15.98 \\
\hline
\end{tabular}

\subsection{Effect of Methanol to SBE Ratio}

The effect of methanol to $\mathrm{SBE}$ ratio was investigated. Six experiments were conducted according to different methanol to SBE ratio with a fixed volume of hexane of $100 \mathrm{ml}$. Table 2 shows the percentage yield of biodiesel yield.

The volume to mass ratio of $200 \mathrm{ml}$ of methanol to 50 gram of SBE resulted in the highest biodiesel yield which is equivalent to $8.09 \mathrm{~g}$ of biodiesel. It shows that the highest ratio of methanol to SBE led to the highest yield of biodiesel. It was due to an increase formation of sodium methoxide from the reactions of methanol and sodium hydroxide. Theoretically, the increase of sodium methoxide leads to an increase in the reaction in which more oil molecules could react. Excess methanol could break the glycerin-fatty acid linkage but if the ratio is further increased, the large amount of excess methanol may slow down the transesterification process [10].

Figure 2 shows the trend of biodiesel yield using different methanol to SBE ratio. It showed the yield of biodiesel was ascending gradually when the ratio of methanol to SBE used increased. It can be seen that yield of biodiesel increasing uniformly when ratio of methanol to SBE increased from 1.2:1 to $2.8: 1$, while from $2.8: 1$ to $3.2: 1$, the yield of biodiesel rise slightly from $15.57 \%$ to $15.98 \%$. Increased the methanol to SBE ratio above 2.8:1 has insignificant effect on the biodiesel yield. Similar results were reported by Miao et al. [10], where they find out large amount of excess methanol may slow down the trans-esterification reaction. This could be due to the dilution of the catalyst.

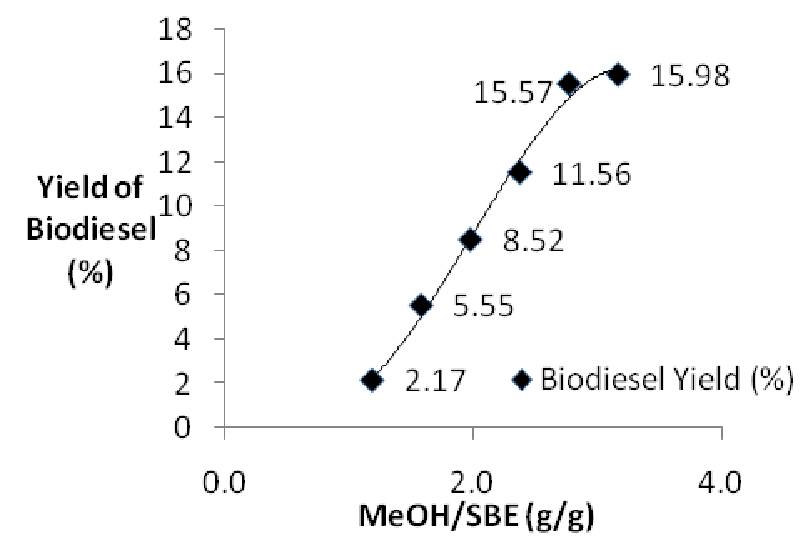

Figure 2. Biodiesel Yield from $50 \mathrm{~g}$ SBE Using Different Methanol to SBE Ratio

Table 3. Biodiesel Yield Using Different Ratio of Hexane to $200 \mathrm{ml}$ of Methanol with $50 \mathrm{~g}$ of SBE

\begin{tabular}{cccc}
\hline $\begin{array}{c}\text { Experi- } \\
\text { ment } \\
\text { No. }\end{array}$ & $\begin{array}{c}\text { Hexane } \\
(\mathbf{m l})\end{array}$ & $\begin{array}{c}\text { Bio- } \\
\text { diesel } \\
\text { Product } \\
\text { Weight } \\
\text { (gram) }\end{array}$ & $\begin{array}{c}\text { Yield } \\
\text { of Bio- } \\
\text { diesel } \\
\text { (\%) }\end{array}$ \\
\hline 1 & 0 & 4.25 & 8.5 \\
2 & 40 & 4.96 & 9.9 \\
3 & 80 & 7.03 & 14.0 \\
4 & 120 & 8.13 & 16.0 \\
5 & 160 & 6.56 & 13.1 \\
6 & 200 & 6.96 & 13.9 \\
\hline
\end{tabular}

\subsection{Effect of Hexane to Methanol Ratio}

A non polar solvent hexane was used to improve the extraction of residual oil from SBE [7]. Thus the study on the effect of hexane in in-situ biodiesel production was carried out. Table 3 shows the biodiesel yield from using different volume of hexane with a fixed volume of $200 \mathrm{ml}$ methanol and $50 \mathrm{~g}$ of SBE.

Result shows that the best volume ratio was $120 \mathrm{ml}$ of hexane to $200 \mathrm{ml}$ of methanol or $0.6: 1$. It is also shown in Figure 3 that by increasing the ratio of hexane to methanol resulted in an increase in the biodiesel yield. Further increasing the ratio of hexane to methanol above 0.8:1 resulted in the decrease of biodiesel yield. The reduction of biodiesel yield was due to side reactions between methanol and hexane with the impurities in SBE, 


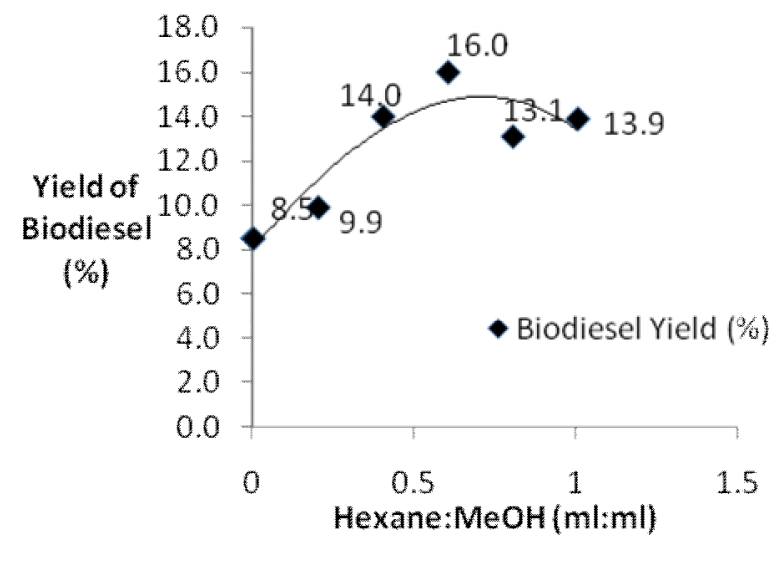

Figure 3. Production of Biodiesel from SBE with Different Hexane to Methanol Ratio using $50 \mathrm{~g}$ SBE

and consequently reduces the rate of reaction in trans-esterification process. In addition, the increased in hexane volume led to the dilution of the oil and sodium methoxide concentration, causing reduction of reaction reactivity and subsequently reducing the rate of reaction and biodiesel yield.

\section{Conclusion}

Two types of catalysts were used in the study and it is demonstrated that alkali catalyst, sodium hydroxide is more suitable for the biodiesel production from dry SBE compared to acid catalyst, sulfuric acid. Results show the highest yield of biodiesel was obtained if sodium hydroxide was used with methanol to SBE ratio of 3.2:1 (gram of methanol: gram of SBE) and hexane to methanol ratio of $0.6: 1$ (volume of hexane: volume of methanol). Furthermore, using the ratio of hexane to methanol above 0.6:1 (volume of hexane: volume of methanol) had caused a decreased in the biodiesel yield.

\section{Acknowledgments}

The authors wish to thank the Ministry of Higher Education for the funding of this project through FRGS project No. 78541.

\section{References}

[1] Huang, Y. P., Chang, J. I., 2009. Biodiesel Production From Residual Oils Recovered From Spent Bleaching Earth. Renewable Energy 35:269-274.

[2] Boukerroui, A., Ouali, M. S., 2000. Regeneration of A Spent Bleaching Earth And Its Reuse In The Refining Of An Edible Oil. Journal of Chemical Technology and Biotechnology. 75:773-776.

[3] Lam, M. K., Lee, K. T., Mohamed, A. R., 2010. Homogeneous, Heterogeneous and Enzymatic Catalysis For Transesterification Of High Free Fatty Acid Oil (Waste Cooking Oil) To Biodiesel: A Review. Biotechnology Advances 28:500-518.

[4] Kheang L. S., Choo Y. M., Ma A. N., 2007. Residual Oil from Spent Bleaching Earth for Biodiesel and Biolubricant Applications. MPOB Information Series.

[5] Choo, Y. M., Yung, C. L., Cheng, S. F.,Ma A. N., Chuah, C. H., Basiron, Y., 2005. Key Fuel Properties Of Palm Oil Alkyl Esters. Fuel. 84:1717-1720.

[6] chuchardt, U., Serchelia, R., Vargas, R. M., 1998. Transesterification of Vegetable Oils: a Review. J. Braz. Chem. Soc.. 9:199-210.

[7] Lee, C. G., Seng, C. E., Liew, K. Y., 2000. Solvent Efficiency for Oil Extraction from Spent Bleaching Clay. JAOCS. 77:1219-1223.

[8] Taylor, D.R., Jenkins, D.B., 1999. Factors Affecting the Pyrophorisity of Spent Bleaching Clay. JAOCS. 67:678.

[9] Demirbas A., 1998. Fuel Properties And Calculation Of Higher Heating Values Of Vegetable Oils. Fuel. 77:1117-1120.

[10] Miao, X. L., Li, R. X., Yao, H. Y., 2008. Effective Acid-CatalyzedTransesterification for Biodiesel Production. Energy Conversion and Management. 50:2680-2684. 